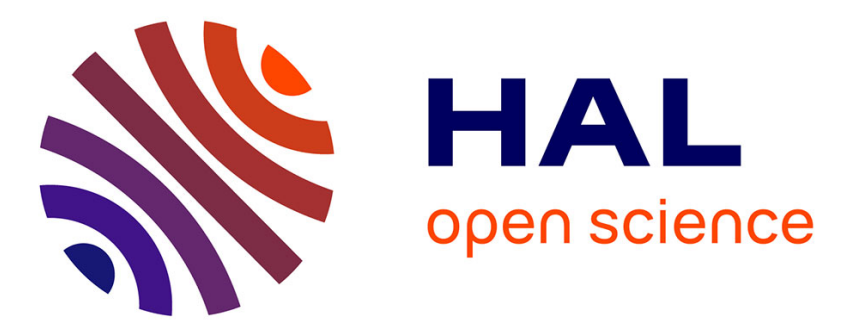

\title{
Remote-sensing measurements in the polar vortex: Comparison to in situ observations and implications for the simultaneous retrievals and analysis of the NO2 and OClO species
}

Gwenaël Berthet, Jean-Baptiste Renard, Valéry Catoire, Michel Chartier, Claude Robert, Nathalie Huret, F. Coquelet, Q. Bourgeois, E.D. Rivière, Brice Barret, et al.

\section{- To cite this version:}

Gwenaël Berthet, Jean-Baptiste Renard, Valéry Catoire, Michel Chartier, Claude Robert, et al.. Remote-sensing measurements in the polar vortex: Comparison to in situ observations and implications for the simultaneous retrievals and analysis of the NO2 and OClO species. Journal of Geophysical Research: Atmospheres, 2007, 112 (D21), pp.D21310. 10.1029/2007JD008699 . hal-00561485

\author{
HAL Id: hal-00561485 \\ https://hal.science/hal-00561485
}

Submitted on 25 Oct 2016

HAL is a multi-disciplinary open access archive for the deposit and dissemination of scientific research documents, whether they are published or not. The documents may come from teaching and research institutions in France or abroad, or from public or private research centers.
L'archive ouverte pluridisciplinaire HAL, est destinée au dépôt et à la diffusion de documents scientifiques de niveau recherche, publiés ou non, émanant des établissements d'enseignement et de recherche français ou étrangers, des laboratoires publics ou privés. 


\title{
Remote-sensing measurements in the polar vortex: Comparison to in situ observations and implications for the simultaneous retrievals and analysis of the $\mathrm{NO}_{2}$ and $\mathrm{OClO}$ species
}

\author{
G. Berthet, ${ }^{1}$ J.-B. Renard, ${ }^{1}$ V. Catoire, ${ }^{1}$ M. Chartier,${ }^{1}$ C. Robert, ${ }^{1}$ N. Huret,${ }^{1}$ F. Coquelet, ${ }^{1}$ \\ Q. Bourgeois, ${ }^{1}$ E. D. Rivière, ${ }^{2}$ B. Barret, ${ }^{3}$ F. Lefèvre, ${ }^{4}$ and A. Hauchecorne ${ }^{4}$
}

Received 24 March 2007; revised 18 July 2007; accepted 3 August 2007; published 13 November 2007.

[1] Nighttime remote-sensing balloon observations conducted by the SALOMON instrument in the arctic polar vortex in January 2006 reveal high amounts of stratospheric $\mathrm{NO}_{2}$ in the lower stratosphere similarly to previously published profiles. $\mathrm{NO}_{2}$ concentration enhancements are also present in the vertical profiles observed by the GOMOS instrument on board the Envisat satellite and obtained coincidently to the balloon measurements. Such quantities are not present in in situ observations obtained by the SPIRALE instrument in similar geophysical conditions. While OClO amounts are acceptably reproduced by Chemistry Transport Model (CTM) calculations, $\mathrm{NO}_{2}$ simulated values are well below the observed quantities. The examination of the slant column densities of $\mathrm{NO}_{2}$ obtained at float altitude highlights unexpected strong enhancements with respect to the elevation angle and displacement of the balloon. It is shown that these fluctuations result from $\mathrm{NO}_{2}$ spatial inhomogeneities located above the balloon float altitude. Potential vorticity maps reveal the presence of midlatitude $\mathrm{NO}_{2}$-rich air in the upper stratosphere or lower mesosphere as a result of the perturbed dynamical situation of the vortex. The presence of spatial inhomogeneities crossed by the lines of sight leads to artificial high concentration values of $\mathrm{NO}_{2}$ in the vertical profile retrieved from the slant column densities assuming spatial homogeneity. A direct implication is that the differences previously observed between measurements of $\mathrm{NO}_{2}$ and $\mathrm{OClO}$ and model results are probably mostly due to the improper inversion of $\mathrm{NO}_{2}$ in the presence of perturbed dynamical conditions or when mesospheric $\mathrm{NO}_{\mathrm{x}}$ production events occur. The dynamical situation will have to be systematically analyzed in future studies involving remote-sensing observations.

Citation: Berthet, G., et al. (2007), Remote-sensing measurements in the polar vortex: Comparison to in situ observations and implications for the simultaneous retrievals and analysis of the $\mathrm{NO}_{2}$ and $\mathrm{OClO}$ species, J. Geophys. Res., 112, D21310, doi:10.1029/2007JD008699.

\section{Introduction}

[2] Remote-sensing measurements from spectrometers on board various platforms (balloons, aircrafts, satellites) have been used for decades to retrieve slant column density (hereafter SCD) values or vertical profiles of the stratospheric chemical compounds. Several studies have focused on the interactions between nitrogen and halogen species which are of primary importance for polar ozone chemistry. Active chlorine species are indeed involved in the ozone

\footnotetext{
${ }^{1}$ Laboratoire de Physique et Chimie de l'Environnement, CNRS and Université d'Orléans, Orléans, France.

${ }^{2}$ Groupe de Spectrométrie Moléculaire et Atmosphérique, Université de Reims and CNRS, Reims, France.

${ }^{3}$ Laboratoire d'Aérologie, Observatoire de Midi-Pyrénées, Toulouse, France.

${ }^{4}$ Service d'Aéronomie, Institut Pierre-Simon Laplace, Paris, France.
}

destroying catalytic cycles whereas nitrogen species act in the deactivation mechanisms of chlorine. Recent work has particularly centered on the $\mathrm{NO}_{2}$ and $\mathrm{OClO}$ species from simultaneous observations by balloon-borne UV-visible spectrometers [Rivière et al., 2002, 2004].

[3] $\mathrm{NO}_{2}$ and $\mathrm{OClO}$ are chemically linked through the following reactions. $\mathrm{OClO}$ is predominantly formed at sunset in the winter polar vortex through one channel of the reaction of $\mathrm{ClO}$ with $\mathrm{BrO}$ :

$$
\begin{aligned}
\mathrm{BrO}+\mathrm{ClO} & \rightarrow \mathrm{OClO}+\mathrm{Br} \\
& \rightarrow \mathrm{ClOO}+\mathrm{Br} \\
& \rightarrow \mathrm{BrCl}+\mathrm{O}_{2}
\end{aligned}
$$

Copyright 2007 by the American Geophysical Union. 0148-0227/07/2007JD008699 
[4] The production of OClO is assumed to be reduced by the two following reactions involving $\mathrm{NO}_{2}$ :

$$
\begin{aligned}
& \mathrm{ClO}+\mathrm{NO}_{2}+\mathrm{M} \rightarrow \mathrm{ClONO}_{2}+\mathrm{M} \\
& \mathrm{BrO}+\mathrm{NO}_{2}+\mathrm{M} \rightarrow \mathrm{BrONO}_{2}+\mathrm{M}
\end{aligned}
$$

[5] From the studies mentioned above it clearly appears that models are not able to reproduce simultaneously the various profiles of $\mathrm{NO}_{2}$ and $\mathrm{OClO}$ measured in the arctic polar vortex. Rivière et al. [2002] have in particular reported high observed quantities of $\mathrm{NO}_{2}$ on 23 January 2000 at altitude levels where full denoxification $\left(\mathrm{NO}_{\mathrm{x}}=\mathrm{NO}+\mathrm{NO}_{2}\right)$ is simulated. Possible sources of $\mathrm{NO}_{2}$ have been invoked to explain the large missing quantities of $\mathrm{NO}_{2}$ in the model calculations. However, such quantities of $\mathrm{NO}_{2}$ lead unequivocally to low simulated amounts of $\mathrm{OClO}$ due to reactions (2) and (3). Rivière et al. [2004] raised the possibility of formation of isomers of $\mathrm{ClONO}_{2}$ and $\mathrm{BrONO}_{2}$ (resulting in a decrease of rate constants of reactions (2) and (3) and an increase of the modeled amounts of OClO) to improve the comparisons between observations and simulations of $\mathrm{OClO}$ and $\mathrm{NO}_{2}$. Canty et al. [2005] have obtained a finer agreement between model results and the balloon observations of $\mathrm{OClO}$ than did Rivière et al. [2002] for the observational case of 23 January 2000. Considering denoxified conditions, they have actually ignored the observed high amounts of $\mathrm{NO}_{2}$ which are in total disagreement with the currently known polar chemistry, an assumption based on the very low levels of NO observed in situ by a chemiluminescence instrument on board the ER-2 [Gao et al., 1997]. This has been achieved by constraining their model with measurements of active bromine and chlorine, increasing one of the branching ratios of the $\mathrm{ClO}+\mathrm{BrO}$ reaction to a value close to the uncertainty upper limit given by 2002 JPL kinetics [Sander et al., 2003] and taking into account various sources of uncertainties in the model. In particular, Canty et al. [2005] have underlined the importance of accurate knowledge of air parcel trajectories for correct modeling of $\mathrm{OClO}$.

[6] Recently, Swartz et al. [2006] have pointed out that spatial inhomogeneities in the line-of-sight measurements from aircraft are likely to affect the retrieval of vertical profiles of species like ozone. Therefore a doubt remains regarding the $\mathrm{NO}_{2}$ quantities measured in the polar vortex, especially in the lower stratosphere where significant amounts of $\mathrm{NO}_{2}$ have been recurrently observed by remotesensing balloon-borne instruments [Sen et al., 1998; Payan et al., 1999; Wetzel et al., 2002; Rivière et al., 2002; Berthet et al., 2003]. A balloon campaign was then conducted in Kiruna (Sweden, $67.9^{\circ} \mathrm{N}, 22.1^{\circ} \mathrm{E}$ ) in the Northern Hemisphere (NH) polar vortex in theoretically denoxified conditions to investigate the $\mathrm{NO}_{2}$ quantities derived from such measurements by comparing them to in situ observations and to model calculations. The observations were made during the night allowing us to get rid of species concentration variations as a function of local time which generally have to be corrected for solar occultation measurements.

\section{Instruments}

[7] Stratospheric profiles were measured by the SALOMON (SALOMON is a French acronym for Spec- troscopie d'Absorption Lunaire pour l'Observation des Minoritaires Ozone et $\mathrm{NO}_{\mathrm{x}}$ ) and SPIRALE (French acronym for Spectroscopie Infrarouge d'Absorption par Lasers Embarqués) balloon-borne instruments used routinely at all latitudes, in particular as part of European and satellite validation campaigns. The performance characteristics of the SALOMON instrument and data reduction method have been described in detail by Renard et al. [2000] and Berthet et al. [2003]. A detailed description of the instrumental characteristics of SPIRALE and of its operating mode is given by Moreau et al. [2005].

[8] SALOMON performs nighttime remote-sensing measurements of $\mathrm{NO}_{2}$ and $\mathrm{OClO}$ from their UV-visible absorption bands using the well-established DOAS (Differential Optical Absorption Spectroscopy) technique [e.g., Platt, 1994]. Note that to our knowledge, no other instrument conducts measurements in the UV-visible wavelength range from a balloon at night. The measurement is selfcalibrated since no assumption concerning the response of the instrument is needed. The spectrometer does not suffer from any kind of mechanical deformations during the moon pointing procedure. The instrument is thermally insulated and thus not affected by external temperature variations. Direct moon spectra are collected and recorded on board the azimuth-elevation-controlled SALOMON gondola. The spectra cover the 340-700 nm wavelength domain and are sampled at $0.34 \mathrm{~nm}$ per pixel. At the balloon float altitude a reference spectrum is recorded when the moon is well above the gondola horizon. This spectrum is carefully chosen so that it contains minimized species absorption features. Owing to the high moon-pointing accuracy, two specific geometries of observation can be carried out to record the raw spectra: (1) at float altitude while the moon sets or rises below the gondola horizon (typical occultation configuration) or (2) during the balloon ascent and at float altitude with the moon located above the gondola horizon (positive elevation angles typically from 0 to $30^{\circ}$ ). The schematic view of the geometry of observation during balloon ascent and at float is presented in Figure 1. Dividing the raw spectra with the reference spectrum gives the transmission spectra highlighting the atmospheric species absorption bands. $\mathrm{NO}_{2}$ and $\mathrm{OClO}$ SCDs are determined respectively over the $420-510$ and $340-420 \mathrm{~nm}$ spectral ranges by least squares fits using the University of Bremen high resolution absorption cross-sections measured at University of Bremen (data available at http://www.iup.physik. uni-bremen.de/gruppen/molspec/index.html). Vertical profiles of the species are obtained by mathematical inversion of the SCD profile using a least squares method based upon the common assumptions of spherical symmetry and homogeneity of the stratospheric layers. Note that for an ascent flight configuration with positive moon elevation angles, Figure 1 represents the stratospheric layers (grey shaded area) crossed by the lines of sight used to retrieve the vertical profile. Concentration error bars are given by three standard deviations in the least squares fit. SALOMON observations were conducted on 16 January 2006 between 1645 UT and 2100 UT in the $14-34 \mathrm{~km}$ altitude range inside the polar vortex during the ascent of the balloon and at float altitude with the moon above the gondola horizon as described in Figure 1. 


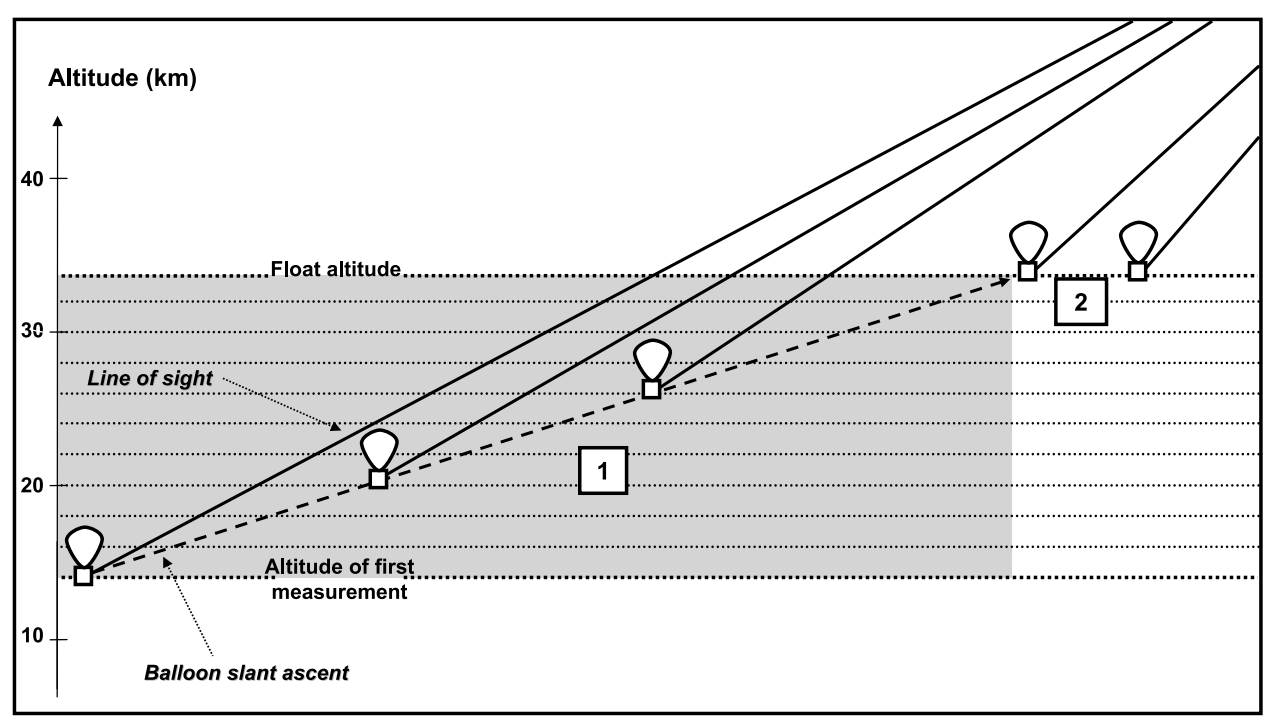

Figure 1. Schematic view of the geometry of observation for SALOMON measurements performed during ascent (1) and at float (2). The grey-shaded area encompasses the stratospheric layers sounded by the infinite lines of sight during ascent and corresponding to the vertical profile retrieved after mathematical inversion of the slant column densities. Homogeneity of these layers is assumed for the retrieval of the concentration vertical profile. Observations conducted at float provide slant column densities varying through increase of moon elevation and horizontal displacement of the balloon.

[9] SPIRALE is dedicated to in situ observations of $\mathrm{NO}_{2}$ and various long-lived and short-lived chemical species from about 10 to $40 \mathrm{~km}$ with a vertical resolution of a few meters. It uses six tunable salt laser diodes in the midinfrared domain $(3 \mu \mathrm{m}$ to $10 \mu \mathrm{m})$ where molecular line strengths are the greatest. The laser diodes are cooled and the beams are injected into a multipass Heriott cell located under the gondola and largely exposed to ambient air. The cell ( $3.5 \mathrm{~m}$ long) is deployed during the flight when pressure is lower than $300 \mathrm{hPa}$. The multiple reflections obtained between the two cell mirrors give a total optical path of $430.78 \mathrm{~m}$. Species concentrations are retrieved from direct infrared absorption, by fitting experimental spectra with spectra calculated using HITRAN 2004 database [Rothman et al., 2005] in the micro-window $1598.4-1598.9 \mathrm{~cm}^{-1}$. The global uncertainties for $\mathrm{NO}_{2}$ have been assessed by taking into account the random errors and the systematic errors, and combining them as the square root of their quadratic sum. In brief, there are two important sources of random errors: (1) the fluctuations of the laser background emission signal and (2) the signal-to-noise ratio. These error sources are the main contributions for $\mathrm{NO}_{2}$ giving a total uncertainty of $30 \%$ at the lower altitudes (around $17 \mathrm{~km}$ ), reduced to $20 \%$ around $24 \mathrm{~km}$, and even to $6 \%$ above $24 \mathrm{~km}$. With respect to the above errors, systematic errors on spectroscopic data (essentially molecular line strength and pressure broadening coefficients) are considered to be negligible. The SPIRALE flight occurred on 20 January 2006 between 1800 UT and 1950 UT with profiles obtained in the vortex between 17 and $27.2 \mathrm{~km}$ under similar time and geophysical conditions as SALOMON for appropriate comparisons.

[10] GOMOS (acronym for Global Ozone Monitoring by Occultation of Stars) on board the European satellite Envisat launched in March 2002 is a space instrument using for the first time a stellar occultation technique to observe stratospheric and mesospheric species that present absorption lines in the UV-visible and near infra red domains (248$942 \mathrm{~nm}$ ) [Bertaux et al., 2004; Hauchecorne et al., 2005]. The reference star spectrum is recorded at the beginning of the occultation outside the atmosphere then occultation spectra are recorded during the set of the star. As those of SALOMON, the GOMOS measurements can be considered self-calibrated. Dedicated to provide a climatology of species involved in the ozone photochemistry, GOMOS provides in particular global $\mathrm{NO}_{2}$ observations with a vertical sampling of about $1.5 \mathrm{~km}$ from about $135 \mathrm{~km}$ down to the lower stratosphere. The $\mathrm{NO}_{2}$ data presented in this study correspond to version V5.0 of the algorithms. Marchand et al. [2004] have analyzed the self-consistency of GOMOS $\mathrm{NO}_{2}$ data using chemical data assimilation and have found no evidence for a bias. The validation work of Renard et al. [2007] shows that the GOMOS individual profiles of $\mathrm{NO}_{2}$ obtained at midlatitude and high latitude compare reasonably well with balloon observations in the middle stratosphere, at least statistically, both in terms of altitudes and concentration values. We therefore assume that GOMOS individual profiles of $\mathrm{NO}_{2}$ can be used for specific comparisons with balloon observations. For such analysis the collocation criteria between GOMOS and balloon observations are typically less than $500 \mathrm{~km}$ in the same physical conditions and less than 3 hours. This was the case for the two balloon flights studied here.

\section{Model Experiment}

[11] The three-dimensional simulations presented here have been performed with the REPROBUS (Reactive 
Processes Ruling the Ozone Budget in the Stratosphere) Chemical Transport Model (CTM) [Lefèvre et al., 1994, 1998] which has been extensively used in previous studies of the stratospheric chemistry especially at high latitudes [e.g., Hoppel et al., 2002; Ricaud et al., 2005]. The model computes the evolution of 55 species through about 160 photolytic gas-phase and heterogeneous reactions with a time step of $15 \mathrm{~min}$ in the present study. 40 species or chemical families, typically long-lived tracers, are transported by a semi-Lagrangian code. The kinetics of all chemical reactions is taken from the 2002 JPL recommendation [Sander et al., 2003], except for the photolysis rate of $\mathrm{Cl}_{2} \mathrm{O}_{2}$ taken from Burkholder et al. [1990] with a wavelength extrapolation to $450 \mathrm{~nm}$ following the work of Stimpfle et al. [2004]. The laboratory measurements of photodissociation cross-sections of $\mathrm{HO}_{2} \mathrm{NO}_{2}$ both in the UV [Knight et al., 2002] and in the near IR [Roehl et al., 2002] have been included in the photodissociation calculations.

[12] We make use here of an improved version of REPROBUS including an explicit description of the inorganic bromine $\left(\mathrm{Br}_{\mathrm{y}}\right)$ budget. The time-dependent sources and chemistries of $\mathrm{CH}_{3} \mathrm{Br}$ and halons (H-1211, $\mathrm{H}-1301, \mathrm{H}-2402)$ are calculated, as well as the additional contribution of bromine very short-lived species [Salawitch et al., 2005], represented in the form of equivalent $\mathrm{CH}_{2} \mathrm{Br}_{2}$ in the model. This additional bromine contribution is set to a value of 6 pptv in REPROBUS compared to the 4-8 pptv range suggested by Salawitch et al. [2005]. This leads to a stratospheric inorganic bromine burden of about 23 pptv calculated by REPROBUS. Monthly varying $\mathrm{H}_{2} \mathrm{SO}_{4}$ fields leading to the formation of liquid aerosols in the CTM are computed from the outputs of a two-dimensional model long-term simulation which takes into account impacts of volcanic eruptions [Bekki et al., 1996]. The heterogeneous chemistry module used in the present simulation includes reactions on binary and ternary liquid aerosols, as well as on water-ice particles. The composition of liquid aerosols is calculated analytically [Carslaw et al., 1995]. The ice particles are assumed to incorporate $\mathrm{HNO}_{3}$ in the form of nitric acid trihydrate (NAT) described by a bimodal size distribution based on the scheme of Davies et al. [2002].

[13] In the present study REPROBUS was integrated from April 2002 to January 2006. The model extends from the surface up to $0.1 \mathrm{hPa}$ on 42 vertical levels resulting in a vertical resolution of about $1 \mathrm{~km}$ in the lower stratosphere. The horizontal resolution is $2^{\circ}$ latitude by $2^{\circ}$ longitude. Species were initialized from the outputs of a long-term simulation (1958-2003) of a two-dimensional model previously used in a variety of atmospheric studies [e.g., Bekki et al., 1994; Bekki and Law, 1997]. REPROBUS was driven by the European Centre for Medium-Range Weather Forecast (ECMWF) meteorological data (temperature, ground pressure and threedimensional winds). The simulation was forced using 3-hourly ECMWF meteorological data constructed from operational analysis and forecasts instead of using common 6-hourly operational analysis. This appears to result in a more accurate modeling of $\mathrm{NO}_{y}$ species as shown by Berthet et al. [2006] for $\mathrm{NO}_{2}$ and $\mathrm{HNO}_{3}$.

\section{Results and Discussion}

\subsection{OClO}

[14] The vertical profile of nighttime OClO concentrations (Figure 2) was measured on 16 January 2006 by SALOMON during the balloon ascent inside the vortex. PSCs were observed above Kiruna over the previous days with cold temperatures recorded and are indicative of the onset of chlorine activation processes. This gives rise to the amounts of $\mathrm{OClO}$ measured by SALOMON on 16 January keeping in mind that $\mathrm{OClO}$ is only a qualitatively good indicator of chlorine activation [Sessler et al., 1995].

[15] Figure 2 shows a comparison of the observed $\mathrm{OClO}$ concentrations to the REPROBUS model calculations. Model profiles were extracted during the simulation to coincide to the varying time and locations of the balloon measurements ranging respectively from 1645 UT to $2100 \mathrm{UT}$ and from $68^{\circ} \mathrm{N}-21^{\circ} \mathrm{E}$ to $69^{\circ} \mathrm{N}-25^{\circ} \mathrm{E}$. The set of these calculated profiles (represented by the shaded area in the plot) thus accounts for the time evolution of the species and considers all the model grid points enclosing the observation positions. Overall, OClO concentrations are acceptably reproduced by the model using the chemical reaction rates of the JPL compilation [Sander et al., 2003] and the ECMWF meteorological fields taking into account both the error bars and the dispersion of the calculated profiles. This result can be considered to be in agreement with the works of Rivière et al. [2002] and Canty et al. [2005] though a model-measurement discrepancy is observed for the two concentration values in the lower part of the vertical profile (Figure 2). It is out of the scope of this paper to perform model sensitivity tests to reduce this discrepancy as thoroughly done by Canty et al. [2005] but possible explanations can be found. These authors show that nighttime $\mathrm{OClO}$ in the Arctic vortex depends on three major factors: the air mass history during the last sunrise and sunset transitions, the branching ratios of the reaction $\mathrm{BrO}+$ $\mathrm{ClO}$, and the amounts of $\mathrm{BrO}_{\mathrm{x}}(\mathrm{BrO}+\mathrm{BrCl})$. Accurate knowledge of these factors is therefore required for an appropriate modeling of nighttime OClO. First, air parcel trajectories are considered to be better simulated in the REPROBUS CTM using 3-hourly ECMWF winds following the results of Berthet et al. [2006] but uncertainties are most likely to remain in the details of air parcel history. Secondly, concerning the branching ratios of the reaction $\mathrm{BrO}+\mathrm{ClO}$, the yield of $\mathrm{BrCl}$ (reaction (1c)) is associated with a large uncertainty range in the 2002 JPL kinetics. Canty et al. [2005] have increased the $\mathrm{BrCl}$ yield to a value of $11 \%$ which is close to the upper limit of the uncertainty. This has resulted in a decrease of the nighttime OClO quantities calculated by an isentropic trajectory model in agreement with the SALOMON observations of 23 January 2000 presented in their study. In our case, we have chosen to compute the $7 \%$ value recommended by JPL since using this upper limit value would have led to a further difference with the SALOMON observations shown in Figure 2. Finally, nighttime $\mathrm{OClO}$ amounts are very sensitive to daytime $\mathrm{BrO}_{\mathrm{x}}$ and to $\mathrm{BrO}$ quantities available in twilight 


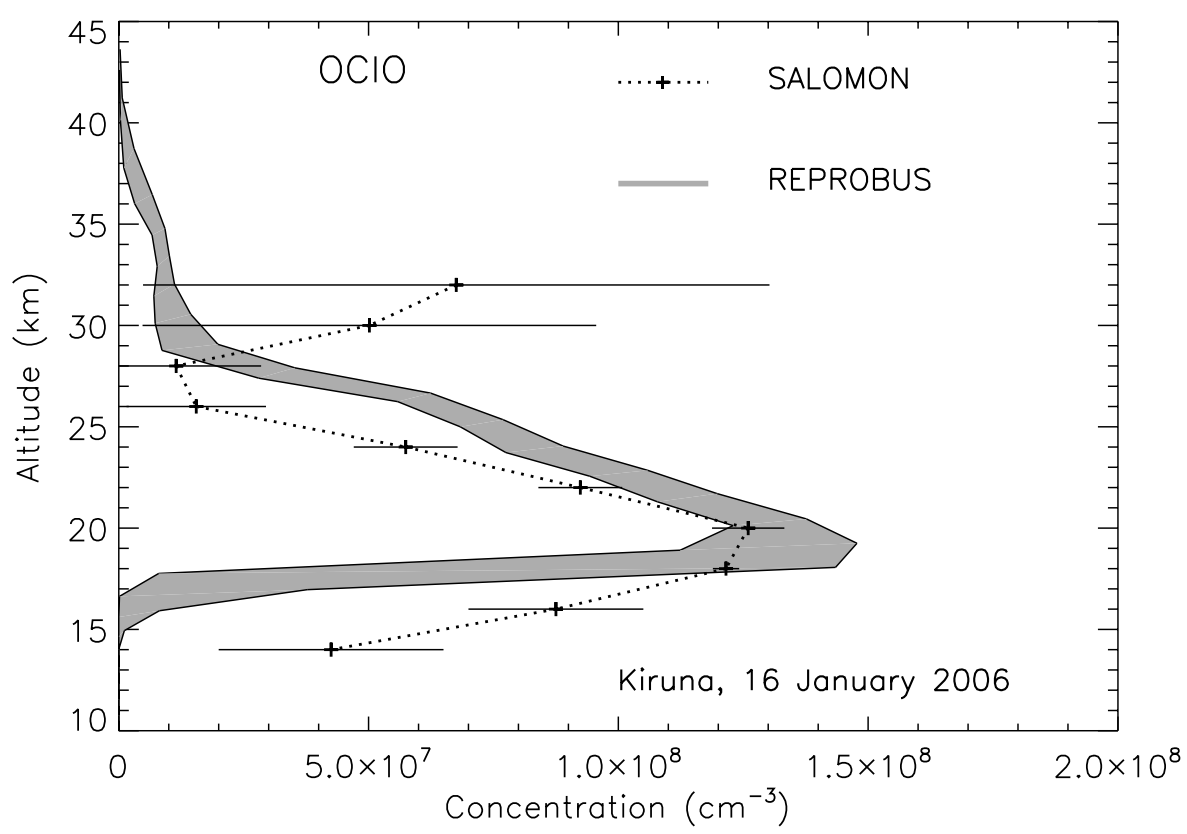

Figure 2. Vertical profile of OClO concentrations measured on 16 January 2006 by SALOMON in the polar night inside the vortex during the balloon ascent. The observed profile is compared to the set of profiles simulated by REPROBUS (expressed by the shaded area in the plot) at the time and positions enclosing the balloon observations ranging from 1645 UT to 2100 UT and from $68^{\circ} \mathrm{N}-21^{\circ} \mathrm{E}$ to $69^{\circ} \mathrm{N}-$ $25^{\circ} \mathrm{E}$.

rather than to the levels of $\mathrm{ClO}_{\mathrm{x}}(\mathrm{ClO}+2 \times \mathrm{ClOOCl})$. The work of Salawitch et al. [2005] strongly suggests that the amount of stratospheric reactive bromine is underestimated in models. Following the results of Salawitch et al. [2005] and as stated in section 3, the 6 pptv additional bromine contribution we have chosen to compute in the upgraded version of REPROBUS could be still underestimated (an upper limit of $8 \mathrm{pptv}$ is suggested by Salawitch et al. [2005]) to correspond to the real amount of stratospheric inorganic bromine. An underestimation of $\mathrm{BrO}_{\mathrm{x}}$ computed in REPROBUS would result in an underestimation of the modeled quantities of $\mathrm{OClO}$ as shown by the sensitivity test done by Canty et al. [2005] at $59 \mathrm{hPa}$ (about $18 \mathrm{~km}$ ). In the case presented in Figure 2 computing REPROBUS without including the additional bromine contribution results in a decrease of simulated amounts of $\mathrm{OClO}$ of about $8 \%$ around $20 \mathrm{~km}$ (but insignificant below about $18 \mathrm{~km}$ ) demonstrating the sensitivity of this species to levels of active bromine at least at some altitude levels (not shown). BrO observations suffer from significant uncertainties and no measurements of $\mathrm{BrCl}$ are currently available. On the basis of these facts it is difficult to constrain the models with very accurate levels of $\mathrm{BrO}_{\mathrm{x}}$ necessary to simulate more confidently nighttime $\mathrm{OClO}$. Note that a better knowledge of $\mathrm{BrO}$ quantities would help for a more accurate modeling of $\mathrm{OClO}$ through a better determination of the $\mathrm{BrCl}$ yield from reaction (1c).

[16] The maximum concentration value of $\mathrm{OClO}$ observed at $20 \mathrm{~km}\left(1.26 \times 10^{8} \mathrm{~cm}^{-3}\right)$ corresponds to a mixing ratio of 75 pptv. From such a typical value of OClO low amounts of $\mathrm{NO}_{2}$ are theoretically expected at these altitude levels.

\section{2. $\mathrm{NO}_{2}$}

[17] Figure 3 presents the $\mathrm{NO}_{2}$ concentration profile from SALOMON observations during the balloon ascent. $\mathrm{A} \mathrm{NO}_{2}$ enhancement is clearly visible below $20 \mathrm{~km}$ as already observed in the polar vortex in previous campaigns. GOMOS observations obtained at comparable time (2000 UT) and location (around $400 \mathrm{~km}$ from SALOMON position; $71.8^{\circ} \mathrm{N}-72.2^{\circ} \mathrm{N} ; 20.2^{\circ} \mathrm{E}-21.8^{\circ} \mathrm{E} ; 2000 \mathrm{UT}$, time differences of $1.5-3.0$ hours) with the SALOMON profile are presented and also reveal a secondary maximum below $20 \mathrm{~km}$. The altitudes of the $\mathrm{NO}_{2}$ maximums are in rather good agreement between the two instruments but SALOMON provides higher concentration values between 18 and $24 \mathrm{~km}$ and between 26 and $28 \mathrm{~km}$. Between 14 and $24 \mathrm{~km}$, note the presence of an oscillation in the GOMOS profile from positive to negative concentration values. Another maximum is present in GOMOS observations around $38 \mathrm{~km}$. Due to the diurnal variation of $\mathrm{NO}_{2}$ the temporal differences between GOMOS and SALOMON may be responsible at least for parts of the deviations between the two instruments.

[18] In Figure 3 the SALOMON observations of $\mathrm{NO}_{2}$ have been compared to a set of profiles simulated by REPROBUS coinciding to the times and locations of the balloon measurements during ascent. Simulated concentrations are significantly below the SALOMON observed values between 20 and $30 \mathrm{~km}$. In particular, as theoretically expected, denoxified conditions are modeled between 20 and $24 \mathrm{~km}$ with values very close to zero compared to measured concentrations of $4.2-1.5 \times 10^{8} \mathrm{~cm}^{-3}(250-$ $170 \mathrm{pptv})$. Below $20 \mathrm{~km}$ the SALOMON profile depicts large error bars but $\mathrm{NO}_{2}$ amounts are shown to be higher than the simulation. The concentration values of $\mathrm{NO}_{2}$ observed by GOMOS and calculated by REPROBUS are of the same amplitude above $31 \mathrm{~km}$, in particular for the secondary peak around $38 \mathrm{~km}$. 


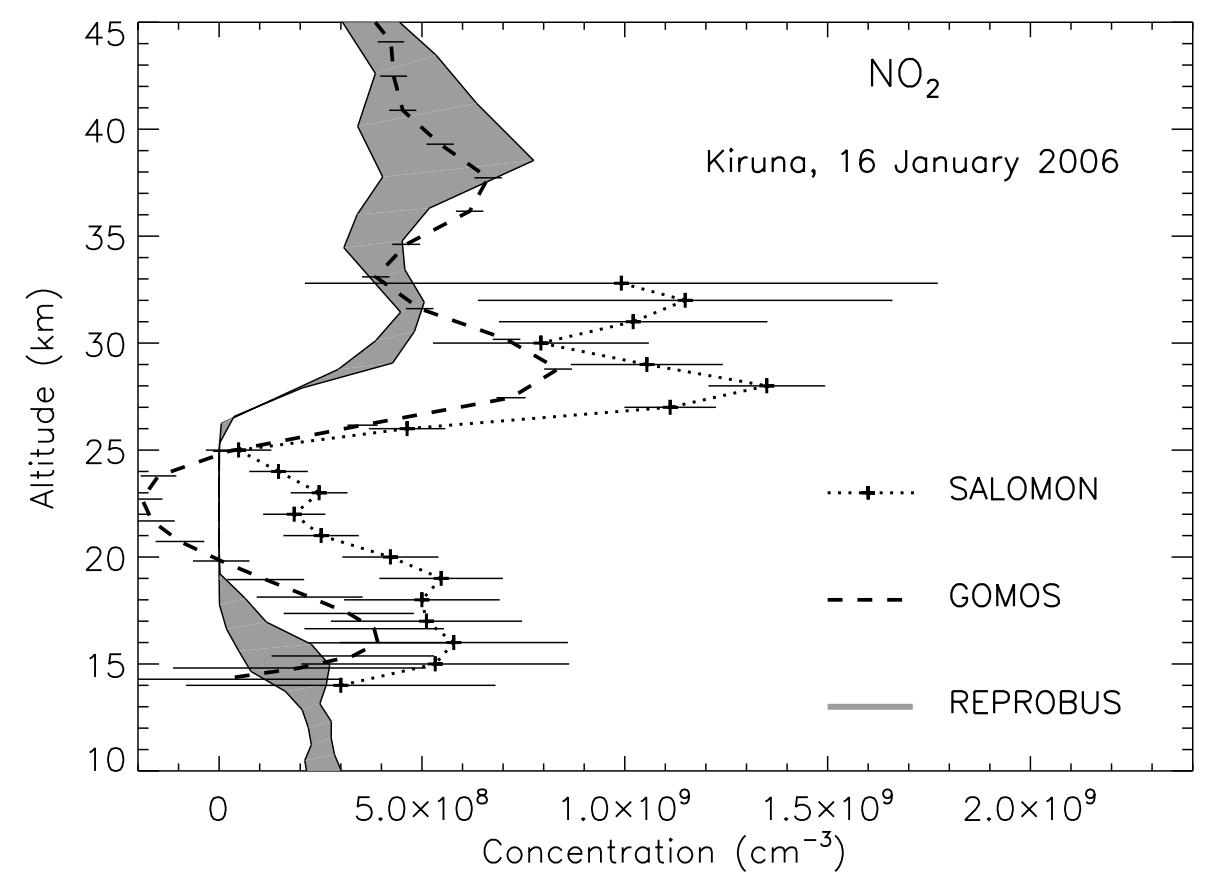

Figure 3. Vertical profile of $\mathrm{NO}_{2}$ from nighttime observations of SALOMON inside the polar vortex on 16 January 2006 (1645-2100 UT). The profile is compared to the GOMOS/Envisat measurements available close to the balloon observations. The results of the REPROBUS simulation set (expressed by the vertical shaded area in the plot) at the time and positions enclosing the balloon observations are presented.

[19] The SPIRALE instrument was launched inside the polar vortex four days after SALOMON. The conditions of measurements are similar to those of SALOMON in terms of time and vortex conditions. In addition, the degree of chlorine activation computed by REPROBUS in the lower stratosphere is around $70 \%$ for both flights. The SPIRALE in situ profile of $\mathrm{NO}_{2}$ was obtained between 1800 UT and 1950 UT (Figure 4) in the $17-27.2 \mathrm{~km}$ altitude range at almost constant latitude-longitude position since the balloon remained close to $67.7^{\circ} \mathrm{N}-21.6^{\circ} \mathrm{E}$ all along the ascent. Comparisons with GOMOS observations (about $500 \mathrm{~km}$ from SPIRALE position; $71.6^{\circ} \mathrm{N}-72.2^{\circ} \mathrm{N} ; 21.3^{\circ} \mathrm{E}-22.2^{\circ} \mathrm{E}$; 1940 UT, time differences up to 1.5 hours) and REPROBUS calculations (taking into account the variation of $\mathrm{NO}_{2}$ during the measurement as in Figure 3) are also presented.

[20] In Figure 4 below $23 \mathrm{~km}$ SPIRALE measurements show denoxification with $\mathrm{NO}_{2}$ concentrations close to zero (accounting for error bars). Surprisingly, this result totally differs from the SALOMON observations presented in Figure 3. One can note that GOMOS observations shown in Figure 3 reveal $\mathrm{NO}_{2}$ amounts higher than zero around 23 $\mathrm{km}$ and below $18 \mathrm{~km}$ which is inconsistent with the results obtained by SPIRALE at these altitude levels. Unlike the REPROBUS-SALOMON comparisons excellent agreement is observed between the in situ profile and the model calculations below $23 \mathrm{~km}$, both data revealing denoxified air masses as expected in the winter polar vortex conditions. Note that in Figure 4 there is no increase in the $\mathrm{NO}_{2}$ concentrations calculated by REPROBUS between 15 and $19 \mathrm{~km}$ unlike the 16 January case (Figure 3). This feature seems to be due to the proximity of the vortex edge at these altitude levels for the 16 January case as revealed by the $\mathrm{N}_{2} \mathrm{O}$ fields computed by REPROBUS (not shown).

[21] Above $23 \mathrm{~km} \mathrm{NO}$ concentrations measured by SPIRALE sharply increase with a gradient similar to the one in the SALOMON profile. The concentration maximum on the SPIRALE profile shows a good agreement with the maximum observed by SALOMON both in terms of altitude and amplitude taking into account the error bars (with for example concentrations of $1.2 \times 10^{9}$ and $1.1 \times 10^{9}$ $\mathrm{cm}^{-3}$ at $27 \mathrm{~km}$ for SPIRALE and SALOMON respectively). At all altitudes above $23 \mathrm{~km}$ a significant underestimation is clearly visible on the profile simulated by REPROBUS (as for the SALOMON-REPROBUS comparison), a discrepancy believed to be partly related to common deficiencies in the calculation of total $\mathrm{NO}_{\mathrm{y}}$ already quantified for midlatitude conditions [Berthet et al., 2006]. One could also argue about the impact of denitrification processes in the vortex not always satisfyingly calculated in CTMs (as can be seen for example in the work of Ricaud et al. [2005] from Odin/REPROBUS comparisons of $\mathrm{HNO}_{3}$ ) and potentially reducing simulated active nitrogen through the link with $\mathrm{HNO}_{3}$. Above $30 \mathrm{~km}$ the broad maximum present in GOMOS observations is also calculated by REPROBUS but with much higher $\mathrm{NO}_{2}$ amounts in the simulation.

[22] From the analysis described above two points appear to be important. First, the analysis of the vertical profiles observed by SALOMON points out another case of simultaneous presence of high amounts of $\mathrm{OClO}$ and $\mathrm{NO}_{2}$, a feature which is not in line with chemical theory as shown from model calculations. Secondly, when remote-sensing observations of $\mathrm{NO}_{2}$ from balloon and satellite are adequately compared to in situ data significant differences are 


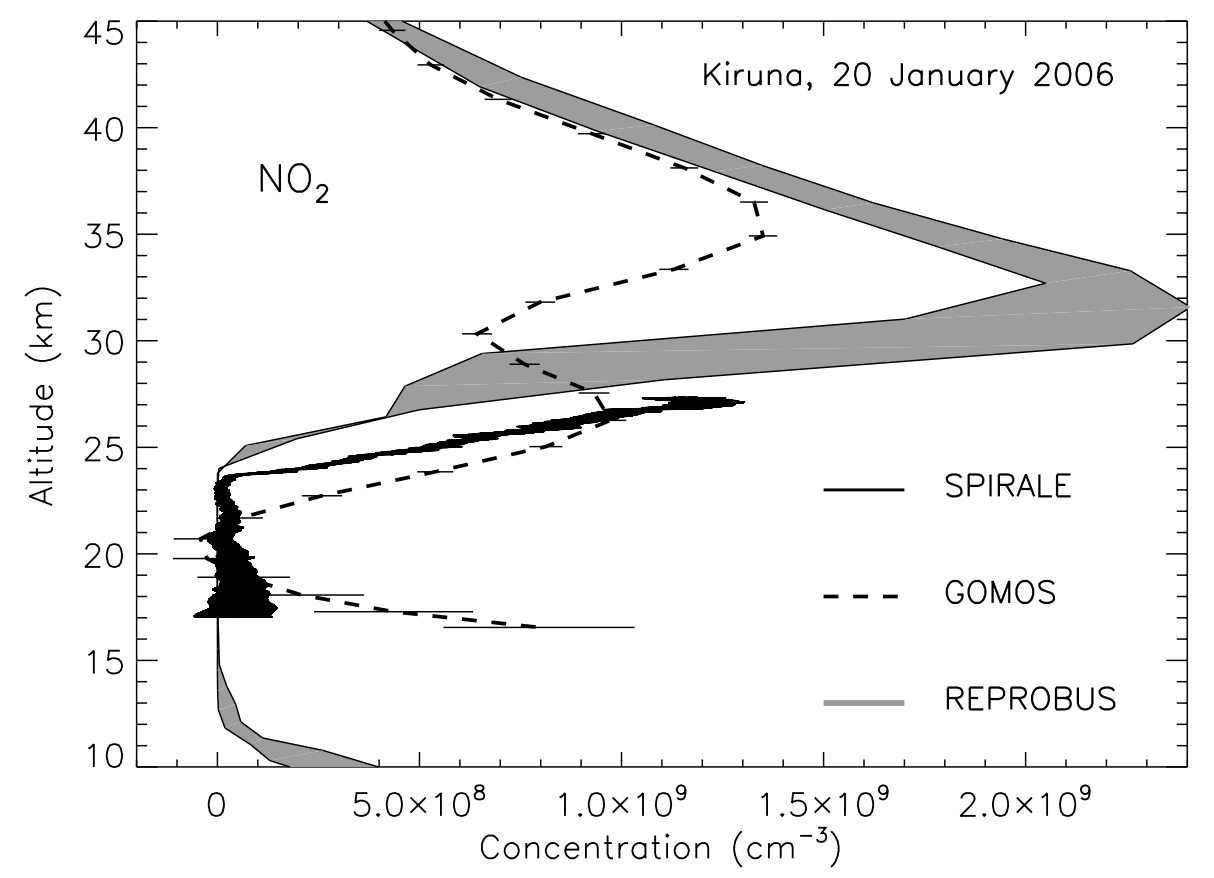

Figure 4. Vertical profile of $\mathrm{NO}_{2}$ from nighttime in situ observations of SPIRALE (around $67.7^{\circ} \mathrm{N}-$ $\left.21.6^{\circ} \mathrm{E}\right)$ inside the polar vortex on 20 January $2006(1800-1950 \mathrm{UT})$. The profile is compared to the GOMOS/Envisat measurements available close to the balloon observations. Also represented are the REPROBUS model calculations as in Figure 2 (shaded area). The thickness of the SPIRALE curve is due to both the high vertical resolution and the error bars.

clearly apparent in the lower stratosphere. The in situ measurements do not confirm the high amounts of $\mathrm{NO}_{2}$ observed by the remote-sensing instruments in air masses expected to be denoxified in the winter polar vortex conditions. These two points together give a hint that remotesensing observations may generate artificial structures at least for altitude levels in the lower stratosphere. The role of spatial inhomogeneities in the atmospheric layers sounded by SALOMON and GOMOS is strongly suspected.

\subsection{Hypothesis of Spatial Homogeneity}

\subsubsection{Dynamical Situation}

[23] To investigate the hypothesis of spatial homogeneity, let us focus on the GOMOS and REPROBUS profiles at altitudes above the balloon measurements. $\mathrm{NO}_{2}$ amounts are usually strongly variable with the altitude depending on the strength of the vortex and on the involved chemical processes. In Figure 3, the enhancement visible between 35 and $40 \mathrm{~km}$ in both REPROBUS and GOMOS profiles appears to be the result of perturbed dynamical conditions. From the Potential Vorticity (PV) map at $950 \mathrm{~K}$ (about $32 \mathrm{~km}$ ) calculated by the MIMOSA advection contour model [Hauchecorne et al., 2002], commonly used to analyze the dynamical conditions encountered during balloon flights [Huret et al., 2006], it seems that some of the ascent lines of sight of SALOMON cross a PV blob reaching the core of the vortex at this level and corresponding to lower PV values than the surrounding vortex air masses (Figure 5). This is likely the signature of extra-vortex air intrusion. The air at stratospheric levels above the balloon float altitude probably experienced significant mixing with $\mathrm{NO}_{2}$-rich air drawn from midlatitudes which manifests itself as the enhancement in $\mathrm{NO}_{2}$ amounts in the $35-40 \mathrm{~km}$ altitude range. The NH polar vortex is often asymmetric and vertically distorted away from the North Pole position resulting in the presence of air advected from midlatitudes to latitudes close to the pole. This was also the case at the time of SPIRALE observations for levels above SPIRALE float altitude as revealed by the large peaks above $30 \mathrm{~km}$ in GOMOS observations, in the REPROBUS model and also by MIMOSA PV fields (Figure 6).

\subsubsection{Slant Column Densities}

[24] Figure 7 presents the $\mathrm{NO}_{2}$ SCDs observed by SALOMON during the ascent of the balloon and at float altitude. It must be noted that these SCD values are obtained relatively to the contribution of $\mathrm{NO}_{2}$ absorption in the reference spectrum considered however to be weak (such contribution is visible as an offset of the whole SCD profile). A flight configuration with positive moon elevation angles provides measurements more sensitive to small scale concentration variations than a typical occultation. At float during a moon set or a moon rise below the gondola horizon, the stratospheric part of the lines of sights reaches several hundred of kilometers contrasting with the several tens of kilometers for an ascent configuration. This gives the possibility of emphasizing the local variations of the species concentrations resulting from the dynamical disturbance. Strong small-scale $\mathrm{NO}_{2}$ oscillations are clearly visible in the ascent pattern of the SCDs in Figure 7. After a careful examination, such SCD fluctuations are not found to be the result of vertical variations or jolts in the balloon trajectory which is rather smooth and monotonic, or simply due to the evolution of the observation geometry (variations of optical paths in the atmospheric layers as the balloon and moon are 


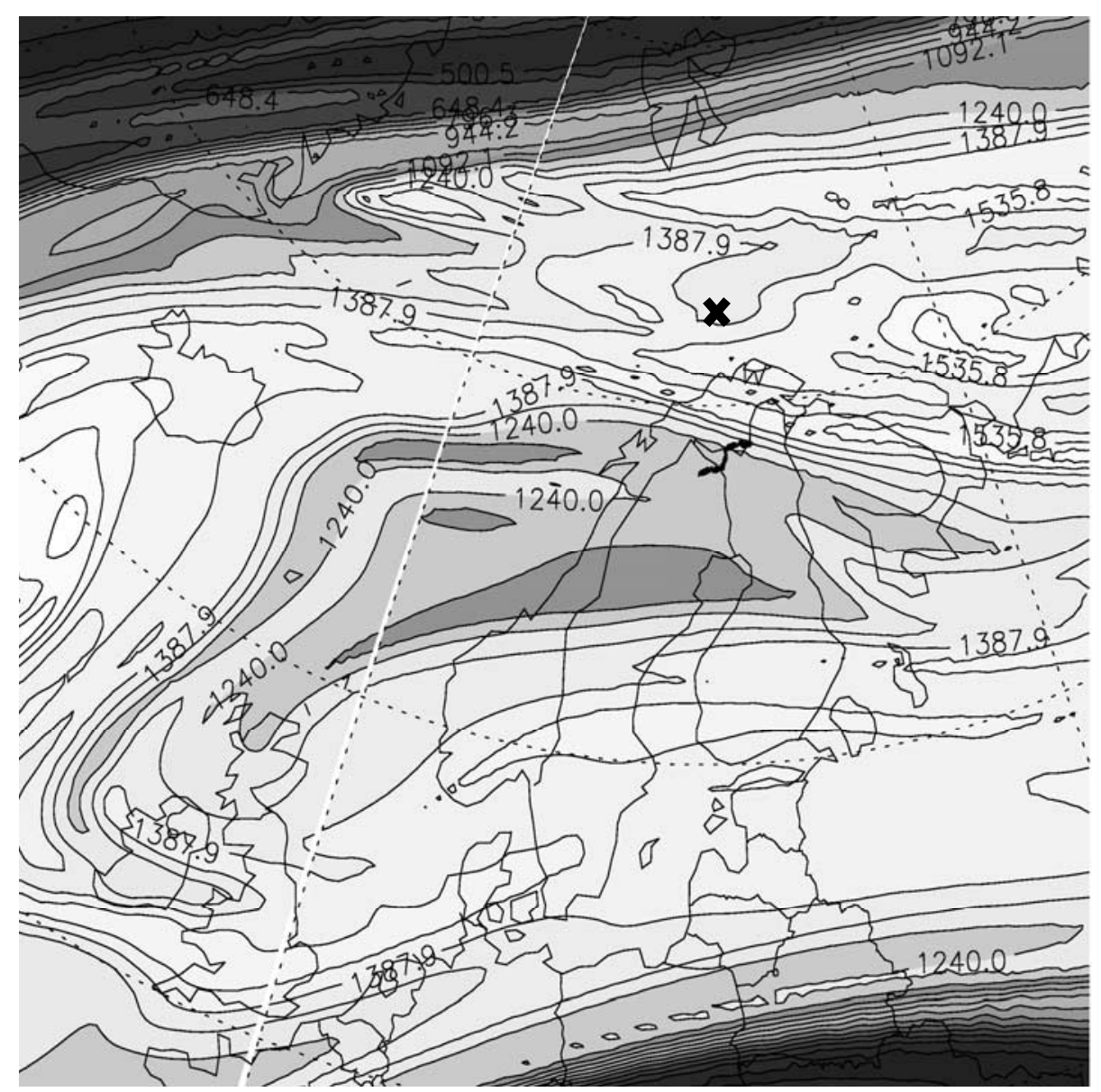

Figure 5. Potential Vorticity isocontours in pvu $\left(1 \mathrm{pvu}=10^{-6} \mathrm{~m}^{2} \mathrm{~s}^{-1} \mathrm{~kg}^{-1} \mathrm{~K}\right)$ calculated by the MIMOSA high-resolution model at $950 \mathrm{~K}$ (about $32 \mathrm{~km}$ ) on 16 January 2006 at 1800 UT. The positions where the lines of sight of SALOMON intersect this level are also shown (bold black line above Scandinavia). GOMOS measurement positions are also shown (thick cross).

rising). The SCD enhancements are superimposed on the rather monotonic SCD trend that one would expect considering the geometry of observation (increasing positive moon elevation angles, displacement of the balloon) and the typical spatial variation of stratospheric $\mathrm{NO}_{2}$. Then these fluctuations, also observed at float (considering that the balloon altitude at float only slightly varies), appear to be the signature of the small-scale variations in the $\mathrm{NO}_{2}$ amounts in the atmospheric layers intersected by some lines of sight as the balloon position varies. This directly reflects the non-uniformity of the layers. In other words the hypothesis of homogeneity is not achieved for the retrieval of $\mathrm{NO}_{2}$ as a result of the dynamical effects described above.

[25] The examination of the $\mathrm{NO}_{2} \mathrm{SCD}$ profiles obtained by GOMOS on 16 and 20 January 2006 coincidently to SALOMON and SPIRALE observations confirms this situation (Figure 8). The two profiles show very similar features with some strong enhancements at and below about $35 \mathrm{~km}$ tangent height, with however a smoother trend above $35 \mathrm{~km}$ on the 20 January data. In a situation of $\mathrm{NO}_{2}$ concentration uniformity and considering the setting star geometry of observation the GOMOS SCD profile should vary more monotonically. The SCD enhancements around $25-27 \mathrm{~km}$ in Figure 8 are due to the concentration maxi- mum of $\mathrm{NO}_{2}$ typically located at these altitude levels. The concentration maximum located around the $35 \mathrm{~km}$ altitude level (Figures 3 and 4) results from the SCD bump clearly present at the corresponding tangent height in Figure 8 and is believed to be the imprint of $\mathrm{NO}_{2}$-rich air intrusions along the GOMOS lines of sight as for the SALOMON case. The $\mathrm{NO}_{2}$ maximum at $35 \mathrm{~km}$ resulting from this intrusion is apparently not crossed by the GOMOS lines of sight corresponding to lower tangent heights. The validity of spatial homogeneity is therefore ruled out in these two cases of GOMOS observations. Note that unlike SALOMON observations, small $\mathrm{NO}_{2}$ variations cannot be emphasized from the observation geometry of GOMOS due to the longer lines of sight.

[26] Note that to explain the $\mathrm{NO}_{2} \mathrm{SCD}$ enhancements shown in Figure 7 one could have suspected an effect of energetic particle precipitation events similar to those recently observed by satellite instruments over southern and northern polar hemispheres [e.g., Randall et al., 2005; Funke et al., 2005; Renard et al., 2006]. Precipitating solar protons and electrons are able to produce large quantities of $\mathrm{NO}_{\mathrm{x}}$ in the mesosphere with subsequent descent to the upper stratosphere. For instance, pronounced enhancements in the vertical column density of $\mathrm{NO}_{2}$ were observed by the 


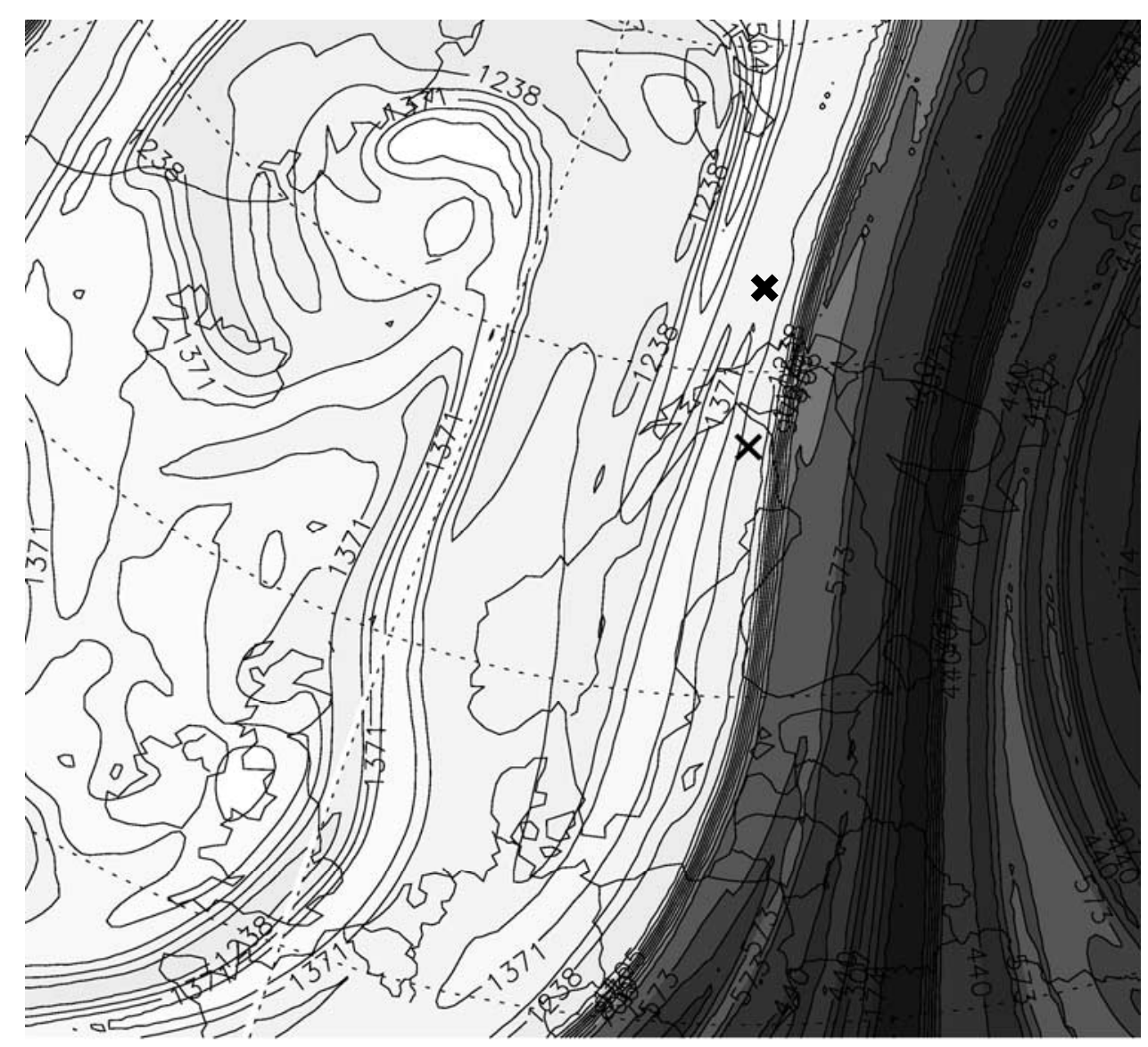

Figure 6. $\mathrm{PV}$ isocontours in pvu $\left(1 \mathrm{pvu}=10^{-6} \mathrm{~m}^{2} \mathrm{~s}^{-1} \mathrm{~kg}^{-1} \mathrm{~K}\right)$ calculated by the MIMOSA highresolution model at $950 \mathrm{~K}$ (about $32 \mathrm{~km}$ ) on 20 January 2006 at 1800 UT. Note the position (black cross) of SPIRALE observations below this level. GOMOS measurement positions are also shown (thick cross).

SAOZ ground-based UV-visible spectrometer in January 2004 above Sodankyla (Finland) and were associated with precipitating particles [Renard et al., 2006]. In this case a concentration maximum of $\mathrm{NO}_{2}$ was detected by the GOMOS and MIPAS instruments at an altitude of about $60 \mathrm{~km}$. Depending on the coverage and horizontal repartition of these events they may corrupt the hypothesis of homogeneity of the layers crossed by the lines of sight of a remote-sensing instrument. In the January 2006 cases studied in this paper no mesospheric $\mathrm{NO}_{\mathrm{x}}$ productions were detected.

[27] Figure 9 shows the $\mathrm{SCD}$ values of $\mathrm{OClO}$ measured by SALOMON. It clearly comes out that OClO SCD pattern presents significant variations resulting from the different natures of air masses crossed by the lines of sight, as for $\mathrm{NO}_{2}$. However, the general trend is different. In Figure 7 $\mathrm{NO}_{2}$ SCDs generally decrease as the moon elevation angle rises whereas OClO SCDs decrease only between 6 and $10^{\circ}$. For higher elevation angles, minimum OClO SCD peaks are close to zero. They can be explained by the midlatitude originating air masses fully lacking in $\mathrm{OClO}$ that are present above the balloon float altitude. The lines of sight cross either these OClO-deprived air masses or OClOrich (and chlorine active) vortex air masses. OClO-deprived air masses may be in chlorine active regions of the stratosphere yet, due to the different solar zenith angle (SZA) dependences of the photolysis efficiencies of $\mathrm{BrCl}$ (the nighttime reservoir of $\mathrm{BrO}$ ) and $\mathrm{OClO}$ [Canty et al., 2005]. Some peaks in Figure 9 can be related to the history of the vortex air masses which can significantly impact the $\mathrm{OClO}$ quantities observed at the time-position of the balloon flight.

[28] We focus now on the SALOMON SCDs obtained at float altitude. In this case the displacement of the balloon is quasi-horizontal and the SCDs are not used for the retrieval of the vertical profile. However, they can be useful to test the consistency of the SALOMON observations toward chemical theory in a geometry of observation corresponding to an air mass number lower than for ascent. Figure 10 presents the fluctuations of the differential SCDs both for $\mathrm{NO}_{2}$ and OClO observed by SALOMON around float altitude. Differential SCDs represented in Figure 10 have been obtained after applying a high-pass filtering procedure allowing the removal of low frequencies (in particular the general trend of each SCD profile). With this procedure only the fluctuations of the $\mathrm{NO}_{2}$ and OClO SCDs become apparent and can be adequately compared. $\mathrm{A} \mathrm{NO}_{2}-\mathrm{OClO}$ SCD anti-correlation is clearly apparent in Figure 10 with opposite features sharply varying from a line of sight to another, in close locations, while one would expect a rather steadily varying trend between $\mathrm{NO}_{2}$ and OClO SCDs in presence of predominantly uniform layers. $\mathrm{A} \mathrm{NO}_{2}-\mathrm{OClO}$ 


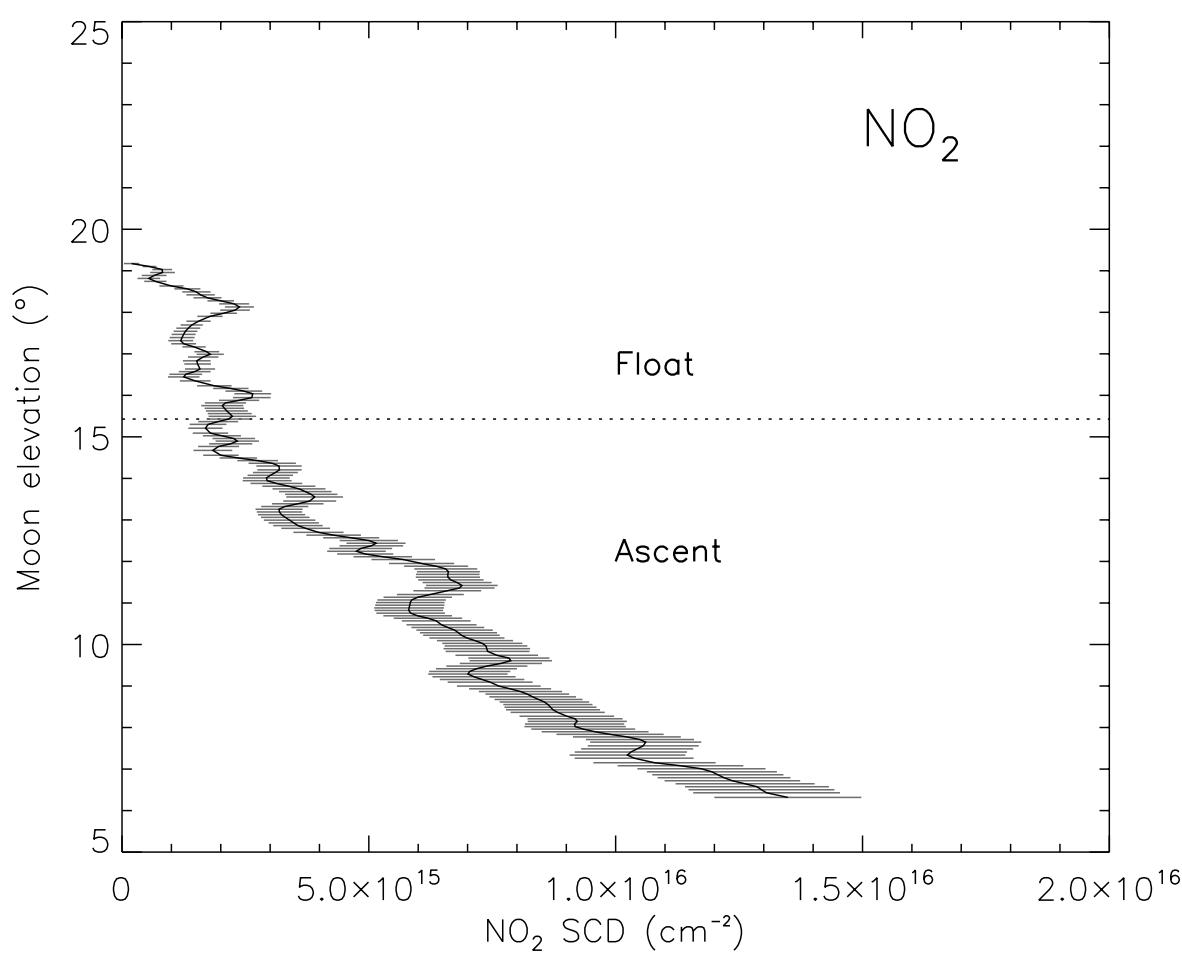

Figure 7. $\mathrm{NO}_{2} \mathrm{SCDs}$ measured by SALOMON for varying moon elevation angles during the balloon ascent and at float altitude (about $33 \mathrm{~km}$ ). Note that the SCD value at $19.5^{\circ}$ corresponds to the spectrum used as reference.

anti-correlation in the SCDs is consistent with the chemical mechanism involving these two species. This is totally in opposition with the conclusions directly inferred from the vertical profiles of $\mathrm{NO}_{2}$ and $\mathrm{OClO}$ (calculated using the
SCDs observed during ascent) suggesting simultaneous presence of significant quantities of these two species.

\subsubsection{Vertical Profiles}

[29] Such variability in the SCD profiles is liable to affect the vertical profile retrieval from the SALOMON ascent

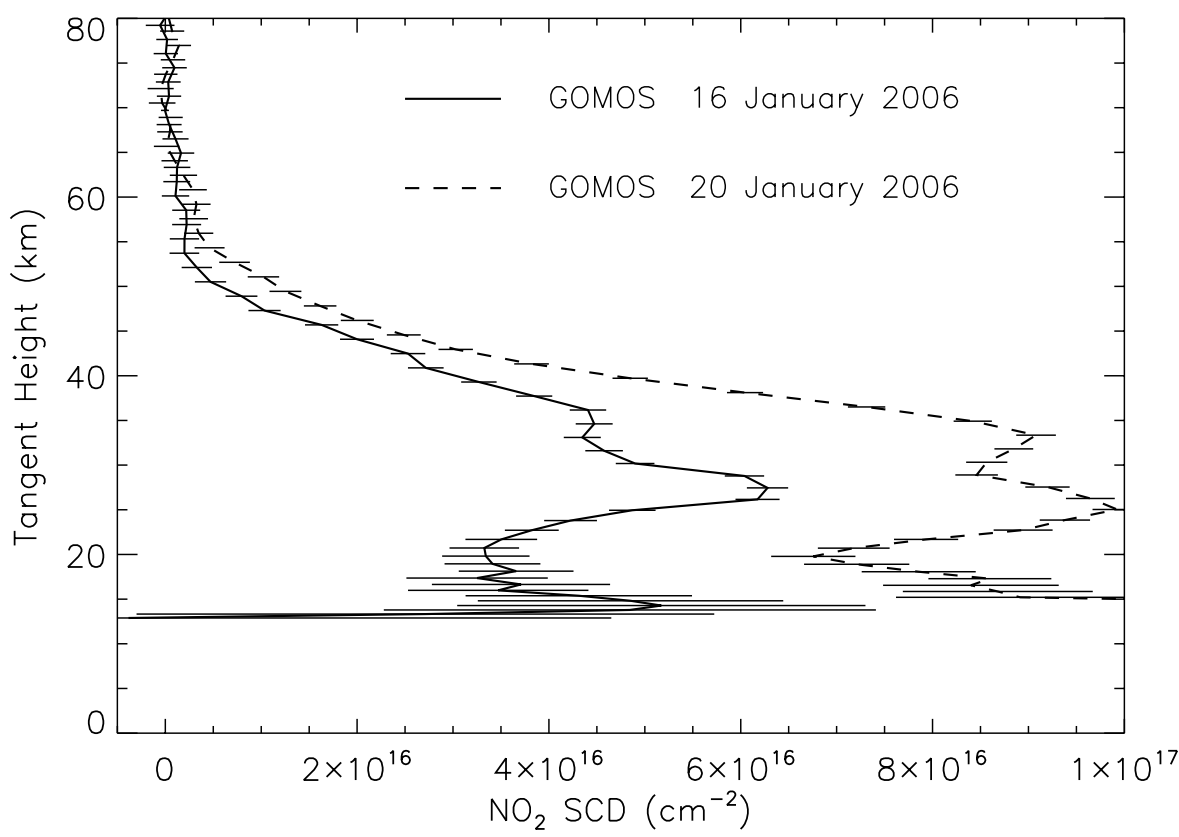

Figure 8. GOMOS SCD values of $\mathrm{NO}_{2}\left(\mathrm{~cm}^{-2}\right)$ versus line-of-sight tangent height $(\mathrm{km})$ obtained on 16 January 2006 coincidently to SALOMON observations and on 20 January 2006 coincidently to SPIRALE observations. The profiles have been sliding-averaged over 3 points. 


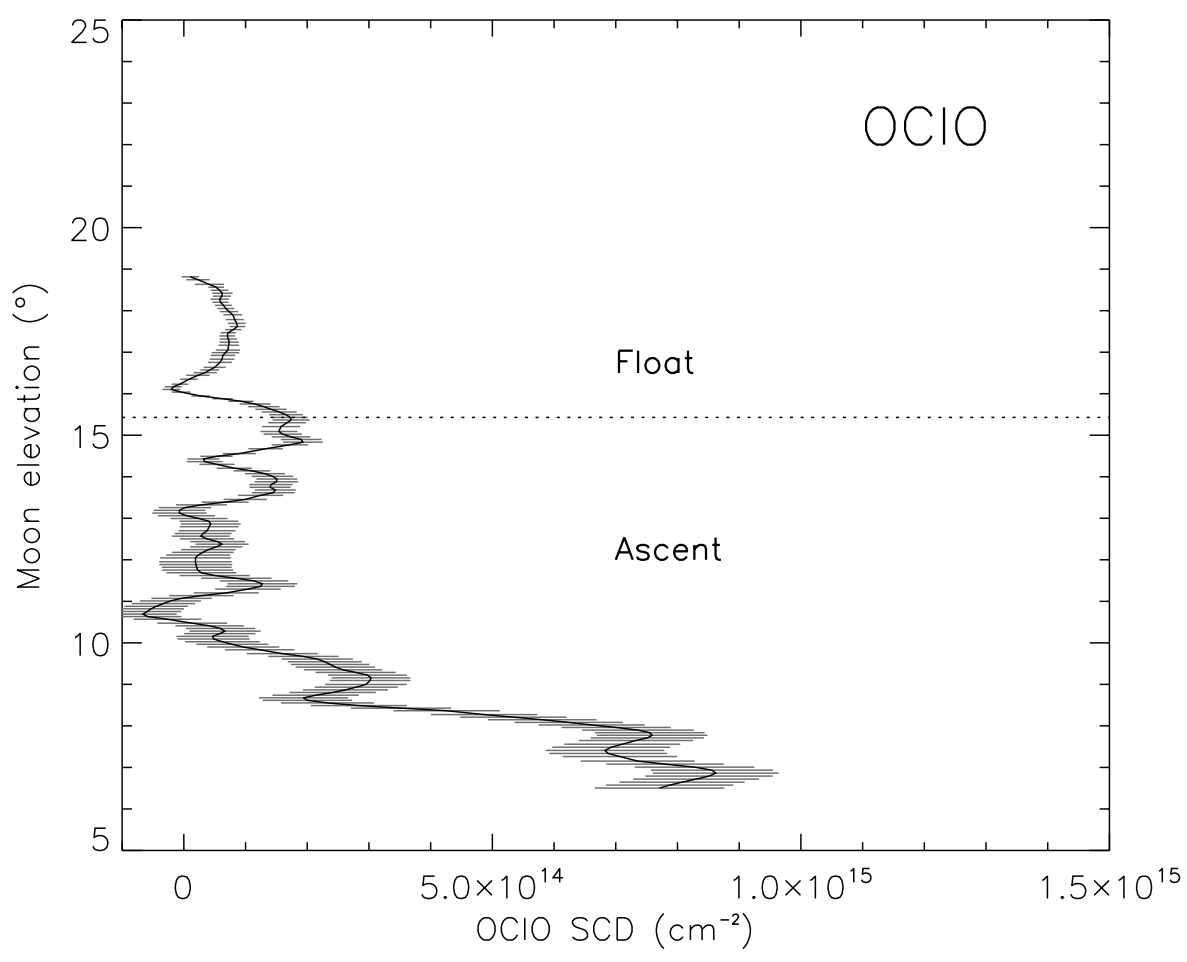

Figure 9. Same as Figure 7 but for OClO.

observations (and subsequently biasing the conclusions inferred from the simultaneous studies of $\mathrm{NO}_{2}$ and $\mathrm{OClO}$ ) when using the spatial least squares inversion that assumes spatial homogeneity. Such method is known to be sensitive to local fluctuations. It is then worth to determine the extent of this effect on the vertical profile retrieval and to try to minimize it. We have performed a qualitative test consisting in fitting the ascent $\mathrm{NO}_{2} \mathrm{SCD}$ profile using polynomials. As a second step the mathematical inversion of the SCD profile fit has been carried out. The process has been reiterated until a satisfactory minimization of the concentration values of $\mathrm{NO}_{2}$ is achieved in the lower stratosphere part of the profile consistent with SPIRALE in situ data and model calculations. Two fits obtained using second-order polynomials are presented in Figure 11. One fit mainly passes through or closely to the minimum values of the SCDs. The newly calculated vertical profile inferred from this fit and shown in Figure 12 clearly reveals $\mathrm{NO}_{2}$ concentration values lower

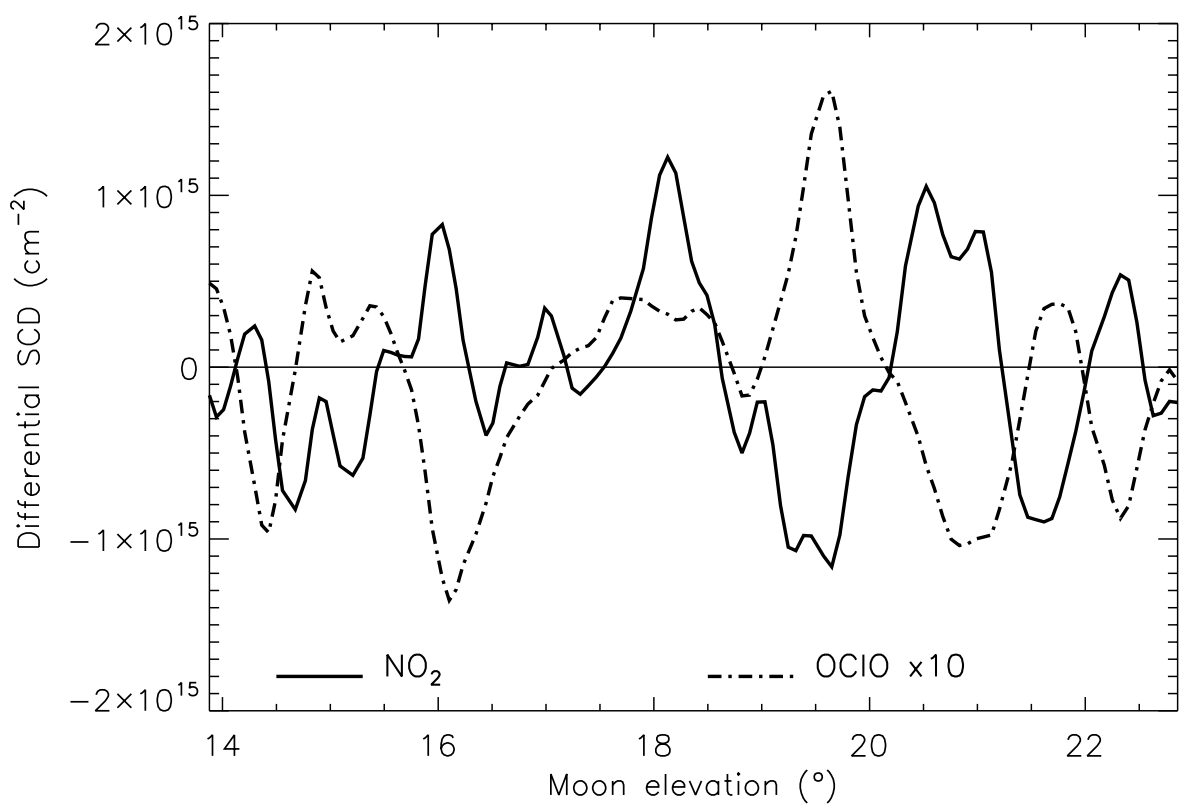

Figure 10. Evolution of the differential $\mathrm{SCDs}$ of $\mathrm{NO}_{2}$ and $\mathrm{OClO}$ measured by SALOMON around the balloon float altitude. OCIO SCDs have been multiplied by 10 for clarity. 


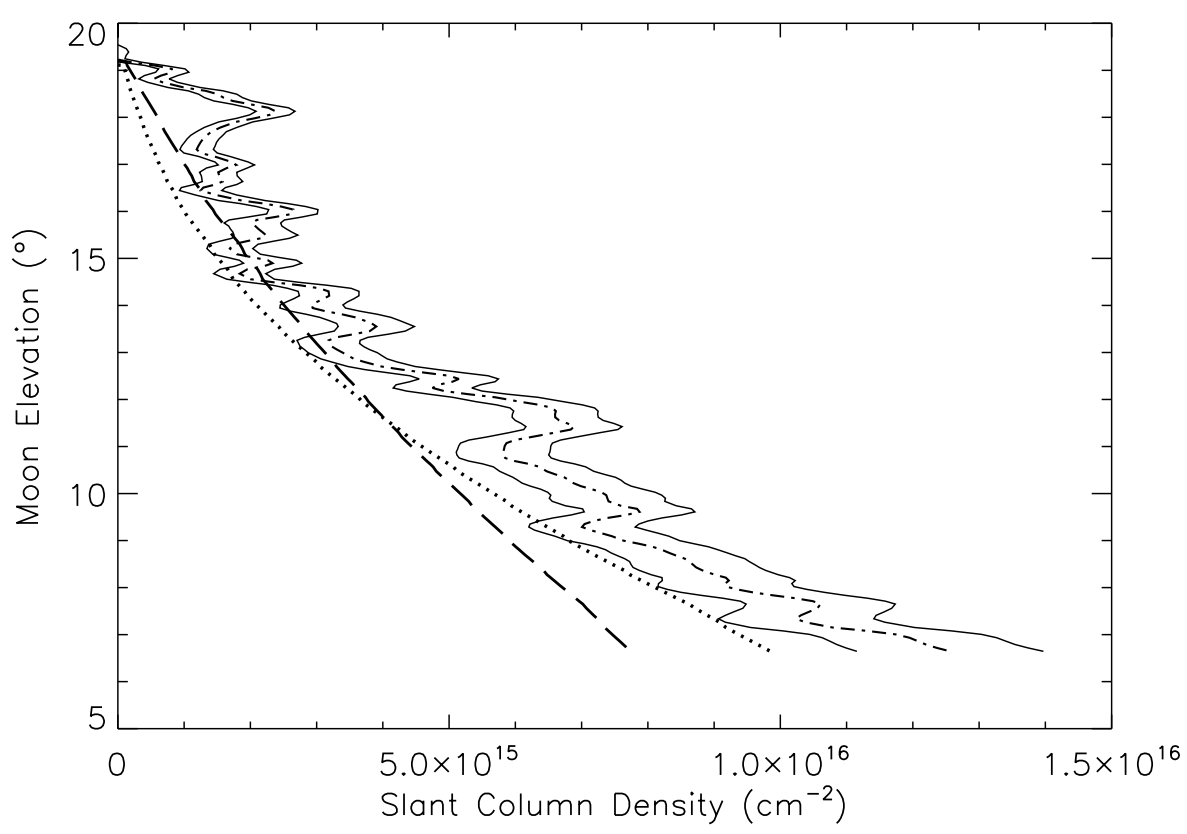

Figure 11. $\mathrm{NO}_{2} \mathrm{SCD}$ profile (including error range) versus moon elevation obtained during the SALOMON balloon ascent together with two fits using second-order polynomials (dashed and dotted lines). The fits are used to calculate concentration values minimized in the lower stratosphere as shown in Figure 12.

than in the initial SALOMON vertical profile and closer to the in situ observations below $23 \mathrm{~km}$. Better agreement is also obtained with the simulated amounts of $\mathrm{NO}_{2}$ at these altitudes and in the $26-29 \mathrm{~km}$ altitude range. The other polynomial fit shown in Figure 11 exhibits a negative bias below $13^{\circ}$ elevation angle but interestingly results in $\mathrm{NO}_{2}$ concentration values close to zero below $23 \mathrm{~km}$ which better capture the in situ observations. This straightforward test reveals the impact of the $\mathrm{NO}_{2} \mathrm{SCD}$ enhancements on the retrieved vertical profile but it does not allow us to remove accurately their contribution.

[30] The $\mathrm{OClO}$ case is rather different. $\mathrm{OClO}$ amounts simulated above $33 \mathrm{~km}$ are a factor of $\sim 10$ below the maximum values at $20 \mathrm{~km}$ (Figure 2). No high altitude

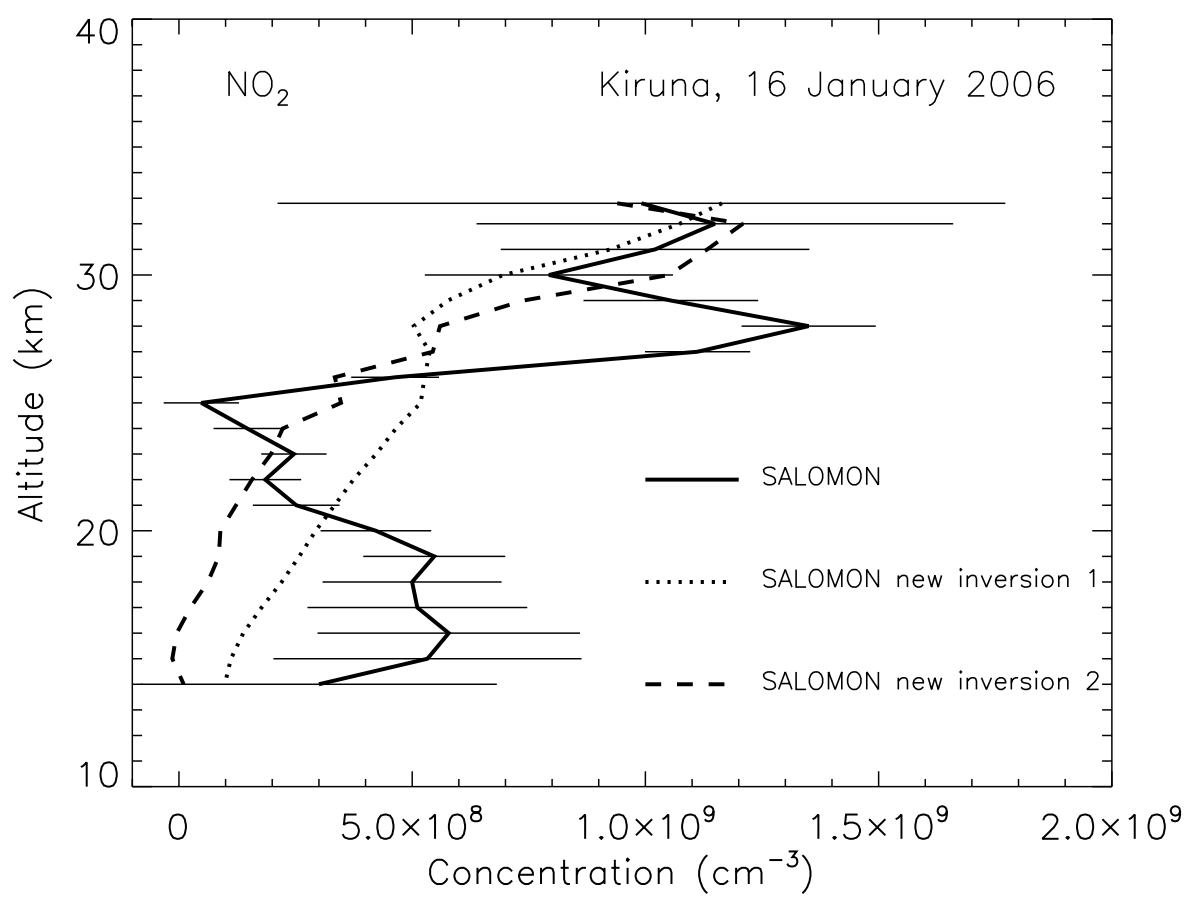

Figure 12. Vertical profiles of $\mathrm{NO}_{2}$ obtained from the SCD test fits shown in Figure 8 (dashed and dotted lines) compared to the initial SALOMON profile (full line). 
concentration enhancement is apparent in the modeled profile since intrusions of midlatitude air above the float altitude bring low amounts of $\mathrm{OClO}$ subsequently mixing to the $\mathrm{OClO}$-abundant vortex air masses, a somewhat opposite feature to the situation for $\mathrm{NO}_{2}$. The upper part of the $\mathrm{OClO}$ vertical profile corresponding to atmospheric layers closer to the dynamically perturbed levels is however characterized by large error bar seen in Figure 2. Then the $\mathrm{OClO}$ inhomogeneities pointed out by the differential SCDs (Figure 10) above the balloon float altitude appear to less impact the inversion process producing the whole vertical profile.

\section{Conclusion}

[31] The observations of three kinds of instruments, two using remote-sensing methods and one using in situ sounding of stratospheric species, have been performed in the Arctic polar vortex in similar geophysical conditions. From the intercomparison of these data, the deficient published measurement-model comparisons regarding the coupling of the chemically linked $\mathrm{NO}_{2}$ and $\mathrm{OClO}$ species appear to be mainly the result of an artifact in the retrieval methods which assume spatial homogeneity. This problem mostly affects the $\mathrm{NO}_{2}$ retrieval by recurrently generating artificial high quantities of $\mathrm{NO}_{2}$ in the lower part of the vertical profiles obtained from the remote-sensing instruments. In the study presented here the homogeneity hypothesis is not achieved in the atmospheric area sounded by the instrument due to the perturbed dynamical conditions with presence of $\mathrm{NO}_{2}$-rich air drawn from midlatitudes resulting in $\mathrm{NO}_{2}$ gradients and anomalous $\mathrm{NO}_{2}$ enhancements in the slant column density profiles. More generally, this is likely to impact occultation observations (with the light source at negative and positive elevation angles) and limb measurements from balloons or satellites, all these types of observations using inversion methods that are not robust to inhomogeneities that can be present from the lower to the upper stratosphere.

[32] Another high-latitude phenomenon may be believed to potentially spoil the hypothesis of homogeneity. Particle precipitation events have been shown to produce high amounts of $\mathrm{NO}_{\mathrm{x}}$ at high altitudes followed by downward transport to the upper stratosphere such as in the 20032004 Arctic winter [Randall et al., 2005; Renard et al., 2006]. If lines of sight intersect those $\mathrm{NO}_{2}$-boosted highaltitude air masses non-uniformly distributed in the layers sounded by the remote-sensing instrument, they are liable to corrupt $\mathrm{NO}_{2}$ retrievals.

[33] Discussing the chemical processes involving the $\mathrm{NO}_{2}$ and $\mathrm{OClO}$ species or more generally the interactions between nitrogen and chlorine families is out of the scope of this paper. But it is clear that analysis of these interactions or studies of the $\mathrm{NO}_{\mathrm{y}}$ chemistry from the remote-sensing data could be biased when lines of sight cross air masses of different origins, which is potentially the case in the vicinity of the polar vortex edge (one could for example think of the $\mathrm{HNO}_{3}$ species showing strong contrast between denitrified vortex air and extra-vortex air), depending on the occurrence of perturbed dynamical situations. The dynamical conditions must then be considered carefully which was not systematically done in some previously published studies. In the case of strong inhomogeneities, inferences drawn from relatively crude analysis of the $\mathrm{NO}_{2}$ and $\mathrm{OClO}$ profiles observed in the future by remote-sensing instruments may be misleading. In this paper we present an analysis based on observations of slant column density variations over a large altitude range and at float altitude. The balloon measurements analyzed in the works of Rivière et al. [2002] and Canty et al. [2005] were not similarly investigated due to the limited altitude range of these observations. The high amounts of $\mathrm{NO}_{2}$ published by Rivière et al. [2002] are difficult to understand considering the current knowledge of stratospheric chemistry. Following our results these quantities are doubtful. However, the conclusion that $\mathrm{OClO}$ chemistry is correctly known in denoxified conditions seems to remain valid.

[34] Next step of this work is to investigate the validity of the homogeneity hypothesis and possible consequences on vertical profiles retrieved at midlatitudes in cases of tropical air intrusions that have been shown to occur at some altitude levels.

[35] Acknowledgments. We would like to thank the space French agency CNES balloon launching team. The SALOMON and SPIRALE flights were founded by ESA and CNES during the Envisat validation project.

\section{References}

Bekki, S., and K. S. Law (1997), Sensitivity of the atmospheric $\mathrm{CH}_{4}$ growth rate to global temperature changes observed from 1980 to 1992 , Tellus, Ser. B, 49(4), 409-416.

Bekki, S., K. S. Law, and J. A. Pyle (1994), Effect of ozone depletion on atmospheric $\mathrm{CH}_{4}$ and $\mathrm{CO}$ concentrations, Nature, 371(6498), 595-597.

Bekki, S., J. A. Pyle, W. Zhong, R. Toumi, J. D. Haigh, and D. M. Pyle (1996), The role of microphysical and chemical processes in prolonging the climate forcing of the Toba eruption, Geophys. Res. Lett., 23, 2669-2672.

Bertaux, J.-L., et al. (2004), First results on GOMOS/ENVISAT, Adv. Space Res., 33(7), 1029-1035.

Berthet, G., J. Renard, M. Chartier, M. Pirre, and C. Robert (2003), Analysis of $\mathrm{OBrO}, \mathrm{IO}$, and $\mathrm{OIO}$ absorption signature in UV-visible spectra measured at night and at sunrise by stratospheric balloon-borne instruments, J. Geophys. Res., 108(D5), 4161, doi:10.1029/2002JD002284.

Berthet, G., N. Huret, F. Lefèvre, G. Moreau, C. Robert, M. Chartier, V. Catoire, B. Barret, I. Pisso, and L. Pomathiod (2006), In situ profiles of $\mathrm{N}_{2} \mathrm{O}, \mathrm{NO}_{2}$ and $\mathrm{HNO}_{3}$ at mid-latitudes retrieved from the SPIRALE balloon-borne instrument, Atmos. Chem. Phys., 6, 1599-1609.

Burkholder, J. B., J. J. Orlando, and C. J. Howard (1990), Ultravioletabsorption cross-sections of $\mathrm{Cl}_{2} \mathrm{O}_{2}$ between 210 and $410 \mathrm{~nm}, J$. Phys. Chem., 94, 687-695.

Canty, T., et al. (2005), Nighttime OClO in the winter Arctic vortex, J. Geophys. Res., 110, D01301, doi:10.1029/2004JD005035.

Carslaw, K., B. Luo, and T. Peter (1995), An analytic expression for the composition of aqueous $\mathrm{HNO}_{3}-\mathrm{H}_{2} \mathrm{SO}_{4}$ stratospheric aerosols including gas phase removal of $\mathrm{HNO}_{3}$, Geophys. Res. Lett., 14, 1877-1880.

Davies, S., et al. (2002), Modeling the effect of denitrification on Arctic ozone depletion during winter 1999/2000, J. Geophys. Res., 107, 8322, doi:10.1029/2001JD000445. [printed 108(D5), 2003]

Funke, B., M. López-Puertas, S. Gil-López, T. von Clarmann, G. P. Stiller, H. Fischer, and S. Kellmann (2005), Downward transport of upper atmospheric $\mathrm{NO}_{x}$ into the polar stratosphere and lower mesosphere during the Antarctic 2003 and Arctic 2002/2003 winters, J. Geophys. Res., 110, D24308, doi:10.1029/2005JD006463.

Gao, R. S., et al. (1997), Partitioning of the reactive nitrogen reservoir in the lower stratosphere of the southern hemisphere: Observations and modeling, J. Geophys. Res., 102, 3935-3949.

Hauchecorne, A., S. Godin, M. Marchand, B. Heese, and C. Souprayen (2002), Quantification of the transport of chemical constituents from the polar vortex to midlatitudes in the lower stratosphere using the highresolution advection model MIMOSA and effective diffusivity, J. Geophys. Res., 107(D20), 8289, doi:10.1029/2001JD000491.

Hauchecorne, A., et al. (2005), First simultaneous global measurements of nighttime stratospheric $\mathrm{NO}_{2}$ and $\mathrm{NO}_{3}$ observed by Global Ozone Monitoring by Occultation of Stars (GOMOS)/Envisat in 2003, J. Geophys. Res., 110, D18301, doi:10.1029/2004JD005711. 
Hoppel, K., R. Bevilacqua, G. Nedoluha, C. Deniel, F. Lefèvre, J. Lumpe, M. Fromm, C. Randall, J. Rosenfield, and M. Rex (2002), POAM III observations of arctic ozone loss for the 1999/2000 winter, J. Geophys. Res., 107(D20), 8262, doi:10.1029/2001JD000476.

Huret, N., M. Pirre, A. Hauchecorne, C. Robert, and V. Catoire (2006), On the vertical structure of the stratosphere at midlatitudes during the first stage of the polar vortex formation and in the polar region in the presence of a large mesospheric descent, J. Geophys. Res., 111, D06111, doi:10.1029/2005JD006102.

Knight, G., A. R. Ravishankara, and J. B. Burkholder (2002), UV absorption cross sections of $\mathrm{HO}_{2} \mathrm{NO}_{2}$ between 343 and $273 \mathrm{~K}$, Phys. Chem. Phys., 4, 1732-1737.

Lefèvre, F., G. P. Brasseur, I. Folkins, A. K. Smith, and P. Simon (1994), Chemistry of the 1991-1992 stratospheric winter: Three-dimensional model simulations, J. Geophys. Res., 99, 9183-9195.

Lefèvre, F., F. Figarol, K. Carslaw, and T. Peter (1998), The 1997 Arctic ozone depletion quantified from three-dimensional model simulations, Geophys. Res. Lett., 25, 2425-2428.

Marchand, M., S. Bekki, A. Hauchecorne, and J.-L. Bertaux (2004), Validation of the self-consistency of GOMOS $\mathrm{NO}_{3}, \mathrm{NO}_{2}$ and $\mathrm{O}_{3}$ data using chemical data assimilation, Geophys. Res. Lett., 31, L10107, doi:10.1029/ 2004GL019631.

Moreau, G., C. Robert, V. Catoire, M. Chartier, C. Camy-Peyret, N. Huret, M. Pirre, L. Pomathiod, and G. Chalumeau (2005), A multi-species in situ balloon-borne instrument with six diode laser spectrometers, Appl. Opt., 44(28), $1-18$.

Payan, S., C. Camy-Peyret, P. Jeseck, T. Hawat, M. Pirre, J.-B. Renard, C. Robert, F. Lefèvre, H. Kansawa, and Y. Sasano (1999), Diurnal and nocturnal distribution of stratospheric $\mathrm{NO}_{2}$ from solar and stellar occultation measurements: Comparison with models and ILAS satellite measurements, J. Geophys. Res., 104, 21,585-21,593.

Platt, U. (1994), Differential optical absorption spectroscopy (DOAS), in Air Monitoring by Spectroscopic Techniques, Chem. Anal., vol. 127, edited by W. M. Sigrist, pp. 27-84, John Wiley, Hoboken. N. J.

Randall, C. E., et al. (2005), Stratospheric effects of energetic particle precipitation in 2003-2004, Geophys. Res. Lett., 32, L05802, doi:10.1029/2004GL022003.

Renard, J.-B., M. Chartier, C. Robert, G. Chalumeau, G. Berthet, M. Pirre, J.-P. Pommereau, and F. Goutail (2000), SALOMON: A new, light balloonborne UV-visible spectrometer for nighttime observations of stratospheric trace-gas species, Appl. Opt., 39(3), 386-392.

Renard, J.-B., P.-L. Blelly, Q. Bourgeois, M. Chartier, F. Goutail, and Y. J. Orsolini (2006), Origin of the January-April 2004 increase in stratospheric $\mathrm{NO}_{2}$ observed in the northern polar latitudes, Geophys. Res. Lett. 33, L11801, doi:10.1029/2005GL025450.

Renard, J.-B., et al. (2007), Validation of GOMOS-ENVISAT vertical profiles of $\mathrm{O}_{3}, \mathrm{NO}_{2}, \mathrm{NO}_{3}$, and aerosol extinction using balloon-borne instruments and analysis of the retrievals, J. Geophys. Res., doi:10.1029/ 2007JA012345, in press.

Ricaud, P., et al. (2005), Polar vortex evolution during the 2002 Antarctic major warming as observed by the Odin satellite, J. Geophys. Res., 110, D05302, doi:10.1029/2004JD005018.
Rivière, E. D., M. Pirre, G. Berthet, J.-B. Renard, F. G. Taupin, N. Huret, M. Chartier, B. Knudsen, and F. Lefèvre (2002), On the interaction between nitrogen and halogen species in the Arctic polar vortex during THESEO and THESEO 2000, J. Geophys. Res., 107, 8311, doi:10.1029/ 2002JD002087. [printed 108(D5), 2003]

Rivière, E. D., M. Pirre, G. Berthet, J.-B. Renard, and F. Lefèvre (2004), Investigating the halogen chemistry from the high-latitude nighttime stratospheric measurements of $\mathrm{OClO}$ and $\mathrm{NO}_{2}$, J. Atmos. Chem., 48, $261-$ 282.

Roehl, C. M., et al. (2002), Photodissociation of peroxynitric acid in the near-IR, J. Phys. Chem., 106, 3766-3772.

Rothman, L. S., et al. (2005), The HITRAN 2004 molecular spectroscopic database: Edition of 2000 including updates through 2001, J. Quant Spectrosc. Radiat. Transfer, 96(2), 139-204.

Salawitch, R. J., D. K. Weisenstein, L. J. Kovalenko, C. E. Sioris, P. O. Wennberg, K. Chance, M. K. W. Ko, and C. A. McLinden (2005), Sensitivity of ozone to bromine in the lower stratosphere, Geophys. Res. Lett., 32, L05811, doi:10.1029/2004GL021504.

Sander, S. P., et al. (2003), Chemical kinetics and photochemical data for use in atmospheric studies, Eval. 14, JPL Publ. 02-25, 334 pp., Jet Propul. Lab., Pasadena, Calif.

Sen, B., G. C. Toon, G. B. Osterman, J.-F. Blavier, J. J. Margitan, R. J. Salawitch, and G. K. Yue (1998), Measurements of reactive nitrogen in the stratosphere, J. Geophys. Res., 103, 3571-3585.

Sessler, J., M. P. Chipperfield, J. A. Pyle, and R. Toumi (1995), Stratospheric OClO measurements as a poor quantitative indicator of chlorine activation, Geophys. Res. Lett., 22, 687-690.

Stimpfle, R. M., D. M. Wilmouth, R. J. Salawitch, and J. G. Anderson (2004), First measurements of $\mathrm{ClOOCl}$ in the stratosphere: The coupling of $\mathrm{ClOOCl}$ and $\mathrm{ClO}$ in the Arctic polar vortex, J. Geophys. Res., 109, D03301, doi:10.1029/2003JD003811.

Swartz, W. H., J.-H. Yee, C. E. Randall, R. E. Shetter, E. V. Browell, J. F. Burris, T. J. McGee, and M. A. Avery (2006), Comparison of highlatitude line of sight ozone column density with derived ozone fields and the effects of horizontal inhomogeneity, Atmos. Chem. Phys., 6, $1843-1852$

Wetzel, G., et al. (2002), NO partitioning and budget and its correlation with $\mathrm{N}_{2} \mathrm{O}$ in the Arctic vortex and in summer midlatitudes in 1997 J. Geophys. Res., 107(D16), 4280, doi:10.1029/2001JD000916.

B. Barret, Laboratoire d'Aérologie, Observatoire de Midi-Pyrénées, 14 Avenue E. Belin, F-31400 Toulouse, France.

G. Berthet, Q. Bourgeois, V. Catoire, M. Chartier, F. Coquelet, N. Huret, J.-B. Renard, and C. Robert, Laboratoire de Physique et Chimie de l'Environnement, CNRS and Université d'Orléans, 3A Avenue de la Recherche Scientifique, F-45071 Orléans Cédex 2, France. (gwenael. berthet@cnrs-orleans.fr)

A. Hauchecorne and F. Lefèvre, Service d'Aéronomie, Institut PierreSimon Laplace, UPMC, 4 Place Jussieu, BP 102, F-75252 Paris, France.

E. D. Rivière, Groupe de Spectrométrie Moléculaire et Atmosphérique, Université de Reims and CNRS, Bâtiment 6, Case 36, BP 1039, F-51687 Reims Cédex 2, France. 